International Journal of Engineering \& Technology, $10(1)(2021) 28-37$
International Journal of Engineering \& Technology
SPC
Website: www.sciencepubco.com/index.php/IJET
Research paper

\title{
Analysis of damage-plasticity model of concrete under uniaxial compression loading
}

\author{
Mohammad Rafiqul Islam ${ }^{1}$, Abbas Ali ${ }^{1}$ *, Md. Jahir Bin Alam ${ }^{1}$, Tanvir Ahmad ${ }^{1}$, Salman Sakib ${ }^{1}$ \\ ${ }^{1}$ Civil and Environmental Engineering Department, Shahjalal University of Science and Technology, Sylhet-3114, Bangladesh \\ *Corresponding author E-mail: sardersust@gmail.com
}

\begin{abstract}
Concrete is a quasi-brittle material and shows different behavior in compression and tension. It shows elastic behavior at initial stage and damage-plasticity behavior beyond elastic limit. Therefore, development of material behavior model of concrete is a complex phenomenon. In this study, concrete damage plasticity theory has been described under experiment on concrete cylinder considering uni-axial compression loading and interpreted with analytical data calculated using CEB-FIP model code equation. The code has divided the stress-strain curve for concrete compression into three sections according to concrete's elastic and non-elastic behaviors. Those three sections have been considered to calculate analytical data. In experiment, concrete behavior has been observed in two phases. The damage value for different stresses at the various points on the stress strain curve has been calculated. According to analytical data, the concrete shows elastic behavior up to $8.3 \mathrm{MPa}$ stress point and no damage occur in the concrete within the limit. However, in experimental data, concrete shows elastic behavior up to only $2.28 \mathrm{MPa}$ and damage occurred beyond the stress. Finally, the percentage of damage of concrete due to compression obtained from analysis and experiment has been assessed and compared. Above 32 percent of concrete damage is found for $22.5 \mathrm{MPa}$ in both cases.
\end{abstract}

Keywords: Concrete Damage; Concrete Elasticity; Concrete Damage-Plasticity Model; CEB-FIP Model Code Equation.

\section{Introduction}

Concrete, mixture of stones, sand, cement and water, is one of the most widely used materials in civil engineering structures as it can be given proper shape according to the design by casting in situ and suitable for almost all weathers. This usefulness increases the demand of concrete day by day and the researchers have been conducting research to understand the behavior of it and to produce better qualified concrete. However, the concrete shows complex behavior under different loadings such as compression and tension and loading patterns such as uniaxial, biaxial and triaxial. The previous concrete researches can be divided into three broad categories-plasticity theory, continuum damage theory and damage plasticity theory.

A significant number of researchers $[11 ; 15-18 ; 20 ; 25 ; 31 ; 33 ; 37 ; 41-42]$ described concrete plasticity theory alone considering pressure and path sensitivities and work or strain hardening. Although this portion may be the widely discussed research section but the researches failed to introduce degradation of material stiffness due to cracking/damage in the concrete.

The second group of researchers $[26 ; 28-29 ; 34-35 ; 38-39]$ worked over the continuum damage theory alone to model the concrete nonlinear behavior. The theory presented effect of micro-cracking with the elastic limit or microscopic level but failed to describe deformation for damage, inelastic volumetric expansion under compression and crack opening effects etc.

Damage plasticity theory of concrete is complex for internal and external variables. Isotropic and anisotropic damage are considered to model of concrete plasticity and damage $[13 ; 19 ; 21 ; 23 ; 27 ; 36]$. Of them, Isotropic damage model is widely used for its simplicity and lucid to understand. Various combinations of stress-based plasticity model such as effective stress model [23-24] and nominal stress model $[1 ; 22 ; 29]$ are proposed in literature.

However, among the other equations and literatures of elastic-damage model of concrete, the most suitable equation is found in CEB-FIP model code [14] published in a technical report for construction materials in London. Same equation is found in the research papers of some researchers Polling and Mark from University of Bochum for its simplicity and may be accuracy. In this paper, the equations have been used to find the analytical data of concrete damage considering elastic and plastic stage. In the experimental test, stress has been applied on concrete cylinders to assess concrete damage behavior.

\section{Nomenclature \\ $\mathrm{E}_{\mathrm{c}}$, modulus of elasticity of concrete \\ $\sigma_{\mathrm{c}}$, stress of concrete}


$\varepsilon_{\mathrm{c}}^{\mathrm{pl}}$, plastic strain

$\mathrm{b}_{\mathrm{c}}$, damage parameter

$\varepsilon_{c}$, strain of concrete

$\sigma_{\mathrm{c}}^{(1)}$, stress of concrete within elastic limit

$\sigma_{c}^{(2)}$, stress of concrete up to peak

$\sigma_{c}^{(3)}$, stress of concrete for post peak zone

$\mathrm{E}_{\mathrm{ci}}$, modified parameter

$\varepsilon_{\mathrm{cl}}$, strain for peak stress

$\gamma_{\mathrm{c}}$, descent function

$\mathrm{f}_{\mathrm{cm}}$, maximum compressive strength

$\mathrm{G}_{\mathrm{cl}}$, constant crushing energy

$\mathrm{I}_{\mathrm{c}}$, side length of column

$\varepsilon_{\mathrm{c}}^{\mathrm{el}}$, elastic strain

$\varepsilon_{\mathrm{c}}^{\text {damage }}$, strain for damage

$\varepsilon_{\mathrm{el}}$, elastic strain

$\varepsilon$ in, inelastic strain

$\varepsilon_{\mathrm{pl}}$, plastic strain

\section{Theory review}

It is said earlier that, CEB-FIP model code and some other equations have been used to find the analytical data of concrete damage considering elastic and plastic stage.

According to CEB-FIP model code [14], the stress-strain relation behavior of concrete under uniaxial compressive loading can be divided into three domains (fig-1). The first section represents the linear-elastic branch that ends at $0.33 \cdot \mathrm{f}_{\mathrm{cm}}\left(\mathrm{where}_{\mathrm{cm}}\right.$ is maximum compressive strength) but by negligible modification, the section is expanded up to $0.4 \cdot \mathrm{f}_{\mathrm{cm}}$. Within the limit, the initial slope of the curve is the Modulus of Elasticity of concrete, $\mathrm{E}_{\mathrm{c}}$ (fig-2).

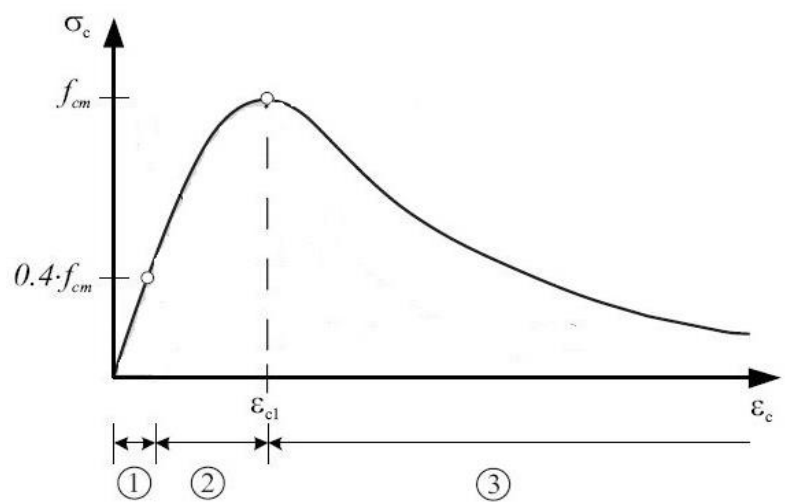

Fig. 1: CEB Model Diagram.

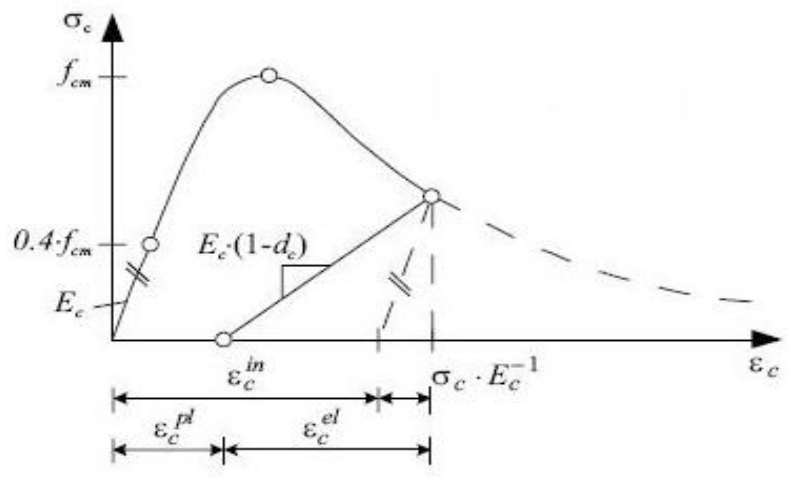

Fig. 2: CEB Model Diagram Considering Damage.

The second section, called rising branch, extends up to the maximum compressive strength, $\mathrm{f}_{\mathrm{cm}}$. Within the section, the strain keeps increasing but inelastic manner. The third section, called post peak zone, is the area after the stress level exceeds maximum compressive strength. The strain seems to increase at a lower stress level at this section and so it is termed as the strain softening zone. In this section, for permanent damage from stiffness in the concrete the slope of the curve decreased. The slope of the curved is denoted as $\mathrm{E}^{\prime \prime}$.

Now, $d_{c}$ is considered as damage factor, the equation presenting the damage formed in the concrete can be written,

$E^{\prime \prime}=\left(1-d_{c}\right) \cdot E_{c}$

Here, $E^{\prime \prime}$ is the tangent of the stress-strain relation for the damage concrete and $\mathrm{E}$ for the undamaged concrete.

Comparing damage factor, $d_{c}$, of CEB-model code equation, damage factor will be: 
$d_{c}=1-\frac{\left(\sigma_{c} \cdot E_{c}^{-1}\right)}{\varepsilon_{c}^{p l} \cdot\left(\frac{1}{b_{c}}-1\right)+\sigma_{c} \cdot E_{c}^{-1}}$

The damage factor is depended on modulus of elasticity of concrete, $E_{c}$, damage parameter, $b_{c}$, stress of concrete, $\sigma_{c}$ and plastic strain, $\varepsilon_{c}^{p l}$.

Modulus of elasticity of concrete, $E_{c}$, can be derived from Neville formula [32].

$E_{c}=57000 \cdot \sqrt{f_{c m}}$

The stress of concrete, $\sigma_{c}$, within the elastic limit, will be the following

$\sigma_{c}^{(1)}=0.4 \cdot f_{c m}$

As elastic behavior is seen in the first section, strain of concrete, $\varepsilon_{c}$, can be found as a linear-elastic function of the secant modulus of elasticity

$\sigma_{c}^{(1)}=E_{c} \cdot \varepsilon_{c}$

For second section, till maximum compressive strength, stress of concrete, $\sigma_{c}$, can be found from the equation

$\sigma_{c}^{(2)}=1-\frac{\left(E_{c i} \cdot \frac{\varepsilon_{c}}{f_{c m}}\right)-\left(\frac{\varepsilon_{c}}{\varepsilon_{c l}}\right)^{2}}{1+\left(E_{c i} \cdot \frac{\varepsilon_{c l}}{f_{c m}}-2\right) \cdot \frac{\varepsilon_{c}}{\varepsilon_{c l}}} \cdot f_{c m}$

Stress of concrete in the second section, $\sigma_{c}^{(2)}$ depends on modified parameter, $E_{c i}$, strain of concrete, $\varepsilon_{c}$, strain for peak stress, $\varepsilon_{c l}$ andmaximum compressive strength, $f_{c m}$.

Strain for peak stress, $\varepsilon_{c l}$, can be adopted from Neville formula [32]

$\varepsilon_{c l}=2 \cdot \frac{f_{c m}}{E}$

The modified parameter, $E_{c i}$, corresponds to the modulus of elasticity can be calculated from the following equation [48]

$E_{c i}=\frac{2}{3 \cdot E_{c}} \cdot\left(\frac{f_{c m}}{\varepsilon_{c l}}\right)^{2}-\frac{4}{3} \cdot \frac{f_{c m}}{\varepsilon_{c l}}+\frac{5}{3} \cdot E_{c}$

For third section, post peak zone, stress of concrete, $\sigma_{c}$, can be found from following equation [43].

$\sigma_{c}^{(3)}=\left(\frac{2+\gamma_{c} \cdot f_{c m} \cdot \varepsilon_{c l}}{2 \cdot f_{c m}}-\gamma_{c} \cdot \varepsilon_{c}+\frac{\gamma_{c} \cdot \varepsilon_{c}^{2}}{2 \cdot \varepsilon_{c l}}\right)^{-1}$

Stress of concrete for the post peak zone, $\sigma_{c}^{(3)}$, depends on descent function, $\gamma_{c}$, strain of concrete, $\varepsilon_{c}$, strain for peak stress, $\varepsilon_{c l}$ andmaximum compressive strength, $f_{c m}$.

The equation of descent function, $\gamma_{c}$, is as below.

$\gamma_{c}=\frac{\pi^{2} \cdot f_{c m} \cdot \varepsilon_{c l}}{2\left[g_{c l}-\frac{f_{c m}}{2} \cdot\left(\varepsilon_{c l} \cdot\left(1-b_{c}\right)+\frac{b_{c} \cdot f_{c m}}{E_{c}}\right)\right]^{2}}$

Descent function, $\gamma_{c}$, depends on constant crushing energy, $g_{c l}$, strain for peak stress, $\varepsilon_{c l}$ andmaximum compressive strength, $f_{c m}$.

Constant crushing energy, $\mathrm{G}_{\mathrm{cl}}$, a material property, is considered its dependency on the geometry of the tested or simulated specimen [40] to almost eliminate mesh dependencies of the simulation results.

$g_{c l}=\frac{G_{c l}}{I_{c}}$

For experimental calculation, equation (1) was modified and found a simplified corollary.

$$
\begin{aligned}
& d_{c}=1-\frac{\left(\sigma_{c} \cdot E_{c}^{-1}\right)}{\varepsilon_{c}^{p l} \cdot\left(\frac{1}{b_{c}}-1\right)+\sigma_{c} \cdot E_{c}^{-1}} \\
& =1-\frac{\left(\sigma_{\mathrm{c}} \cdot \mathrm{E}_{\mathrm{c}}^{-1}\right)}{\left(\frac{\varepsilon_{\mathrm{c}}^{\mathrm{pl}}}{\mathrm{b}_{\mathrm{c}}^{\mathrm{p}}}-\varepsilon_{\mathrm{c}}^{\mathrm{p}}\right)+\sigma_{\mathrm{c}} \cdot \mathrm{E}_{\mathrm{c}}^{-1}} \\
& =1-\frac{\left(\sigma_{\mathrm{c}} \cdot \mathrm{E}_{\mathrm{c}}^{-1}\right)}{\left(\varepsilon_{\mathrm{c}}^{\mathrm{in}}-\varepsilon_{\mathrm{c}}^{\mathrm{pl}}\right)+\sigma_{\mathrm{c}} \cdot \mathrm{E}_{\mathrm{c}}^{-1}}\left[\text { As we know, } \varepsilon_{\mathrm{c}}^{\mathrm{pl}}=\varepsilon_{\mathrm{c}}^{\mathrm{in}} \cdot \mathrm{b}_{\mathrm{c}}\right]
\end{aligned}
$$

So, $\mathrm{d}_{\mathrm{c}}=1-\frac{\varepsilon_{\mathrm{c}}^{\mathrm{el}}}{\varepsilon_{\mathrm{c}}^{\text {damage }}+\varepsilon_{\mathrm{c}}^{\mathrm{el}}}$

From the equation, it can be said that, damage of concrete, $\mathrm{d}_{\mathrm{c}}$, depends on elastic strain, $\varepsilon_{\mathrm{c}}^{\mathrm{el}}$, and strain for concrete damage, $\varepsilon_{\mathrm{c}}^{\text {damage }}$. 


\section{Procedures}

\subsection{Materials}

For the total procedure (concrete preparation and testing), ASTM guidelines were followed. Crushed stones of quarry, Sylhet sand and Ordinary Portland Cement (OPC) were used as coarse aggregate, fine aggregate and cement respectively. OPC used in this study has clinker and gypsum as $95 \%$ or above and $0-5 \%$ respectively which confirms to the ASTM [6].

Volumetric amount for coarse aggregates were taken according to table 1 following ASTM [9]. Sieve analysis for fine aggregate was done according to ASTM [5], the result of sieve analysis is listed in table-2.

Table 1: Volumetric Amount of Course Aggregates (Crushed Stone)

\begin{tabular}{|c|c|c|c|c|c|c|}
\hline \multirow{2}{*}{\multicolumn{2}{|c|}{$\begin{array}{l}\text { Stone size } \\
\text { Percent in Volume }(\%)\end{array}$}} & & \multirow{2}{*}{$25.0 \mathrm{~mm}(1 \mathrm{in})$} & \multicolumn{2}{|c|}{$19.0 \mathrm{~mm}(3 / 4 \mathrm{in})$} & \multirow{2}{*}{$\frac{12.5 \mathrm{~mm}(1 / 2 \mathrm{in})}{25}$} \\
\hline & & & & 75 & & \\
\hline Passing (\%) & 100 & 87 & 68 & 36 & 5 & 00 \\
\hline Retain (\%) & 00 & 13 & 32 & 64 & 95 & 100 \\
\hline
\end{tabular}

Following the rules of ASTM [2; 4], tests for fineness Modulus, bulk density, specific gravity and water absorption of sand and crushed stone were done and values are listed in table 3.

Table 3: Properties of Fine and Coarse Aggregates

\begin{tabular}{lllll}
\hline Aggregates & Fineness Modulus & Bulk density $\left(\mathrm{kg} / \mathrm{m}^{3}\right)$ & Specific gravity & Water absorption $(\%)$ \\
\hline Fine (Sand) & 3.04 & 1413 & 2.64 & 0.98 \\
Coarse (Crushed stone) & 6.87 & 1480 & 2.89 & 0.60 \\
\hline
\end{tabular}

\subsection{Preparation and test}

Following the BNBC [12], the volumetric ratio of cement, fine aggregates and coarse aggregates were taken 1:1.5:3. The ratio of water and cement was taken 0.45. Mixture was done following ASTM [8]. Following ASTM [7], 8 inches (200 mm) height and 4 inches (100 $\mathrm{mm}$ ) were selected to casting the cylinders. Casting, compacting and curing were done following ASTM [7]. For compacting, a $300 \mathrm{~mm}$ long and $10 \mathrm{~mm}$ diameter rod was selected. Almost equal height of two layers was considered during casting and 25 numbers of roddings were done for each layer. 24 hours after casing the cylinders were de-molding and kept up to 48 hours in room temperature. Then the cylinders were cured fully submerged condition (fig 3) in a tank for 28 days. Slump test of concrete was done following ASTM [10] and found satisfactory result.

Total 15 cylinders of were made, 3 of them were used to find the ultimate strength of concrete and that was $22.25 \mathrm{MPa}$. Rest of the concrete cylinders has been used to evaluate damage of concrete. Following ASTM [3] rules, The Universal testing machine (UTM) was used to find compressive strength of each cylinder. To get strain-stress curve, twelve projected stress points were selected within elastic and non-elastic zones considering ultimate strength of concrete, but no point was taken in post peak zone (literature review) for experimental tests. According to stress in unit MPa, twelve projected stress points-1, 1.5, 2.5, 5, 7.5, 10, 12.5, 15, 17.5, 20, 21.5, 22.25-were selected in elastic zone and in non-elastic zone.

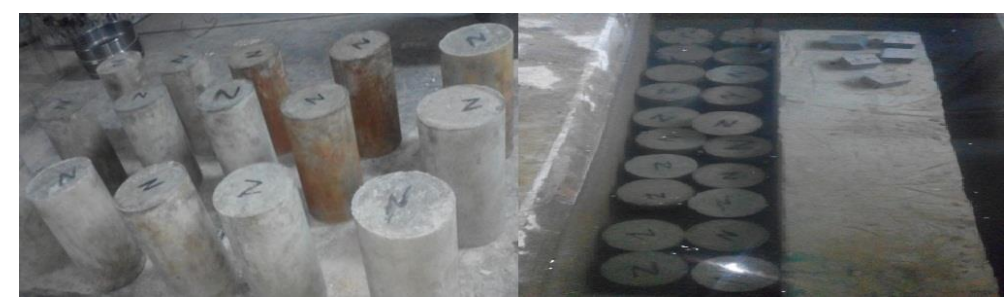

Fig. 3: Cylinders Before and During Curing.

Then one cylinder was placed on UTM and pressed to stress $1 \mathrm{MPa}$ (first point) and released the load. The stress-strain data was collected and it was called initial state data and marked Phase-1 in the graph. Again, the cylinder was compressed till it was collapsed (fully damaged) and collected stress-strain data. The data was called final state data and marked Phase-2 in graph.

The second cylinder pressed to stress $1.5 \mathrm{MPa}$ (second point) and the rest of the procedures were followed same as previous cylinder and second graph was plotted. The whole procedure was performed for the other points and plotted graph for each point (each cylinder). A total 12 graph was plotted for 12 points.

\section{Result analyses}

For analytical data, equations 1 to 10 (theory review section) have been used to calculate strain for certain stresses in different twenty points within three zones. A table has been made by analytical data (Table-4) and graphs have been formed (Fig 4-15).

Following data were taken to calculate damage parameter.

Peak stress (Ultimate strength of concrete), $\mathrm{f}_{\mathrm{cm}}=22.25 \mathrm{MPa}$ (From experiment)

Damage parameter, $b_{c}=0.7$ [44]

Crushing and fractures energies, $G_{\mathrm{cl}}=19 \mathrm{~N} / \mathrm{mm}$

Side length of column, $\mathrm{I}_{\mathrm{c}}=200 \mathrm{~mm}$ 
Table 4: Damage Variable $\mathrm{D}_{\mathrm{c}}$, Elastic Strain, $\mathrm{E}_{\mathrm{el}}$, In-Elastic Strain, $\mathrm{E}_{\mathrm{in}}$ and Plastic Strain, $\mathrm{E}_{\mathrm{pl}}$ from Analysis

\begin{tabular}{|c|c|c|c|c|c|c|c|}
\hline S1. No. & Zone & Stress, $\sigma \mathrm{Mpa}$ & Strain(el), $\varepsilon_{\mathrm{el}} \%$ & Strain (in), $\varepsilon_{\text {in }} \%$ & Strain(pl), $\varepsilon_{\mathrm{pl}} \%$ & Damage Variable, $\mathrm{d}_{\mathrm{c}}$ & $\mathrm{d}_{\mathrm{c},}(\%)$ \\
\hline 1 & Elastic, 1 & 1.8 & 0.0047 & 0 & 0 & 0 & 0 \\
\hline 2 & Elastic, 1 & 2.3 & 0.0067 & 0 & 0 & 0 & 0 \\
\hline 3 & Elastic, 1 & 3.4 & 0.0115 & 0 & 0 & 0 & 0 \\
\hline 5 & Elastic, 1 & 8.3 & 0.034 & 0 & 0 & 0 & 0 \\
\hline 6 & Elastic, 1 & 8.97 & 0.04 & 0 & 0 & 0 & 0 \\
\hline 7 & Plastic, 2 & 10.33 & 0.0457 & 0.0057 & 0.00399 & 0.0367 & 3.67 \\
\hline 8 & Plastic, 2 & 10.5 & 0.0483 & 0.0075 & 0.00525 & 0.0464 & 4.64 \\
\hline 10 & Plastic, 2 & 12.74 & 0.063438 & 0.022 & 0.0154 & 0.104 & 10.4 \\
\hline 11 & Plastic, 2 & 13.5 & 0.067496 & 0.027 & 0.0189 & 0.103 & 10.3 \\
\hline 12 & Plastic, 2 & 14.287 & 0.073436 & 0.0324 & 0.02268 & 0.132 & 13.2 \\
\hline 13 & Plastic, 2 & 15.1 & 0.0788 & 0.038 & 0.0266 & 0.146 & 14.6 \\
\hline 14 & Plastic, 2 & 16.0 & 0.096522 & 0.059 & 0.0413 & 0.186 & 18.6 \\
\hline 15 & Plastic, 2 & 18.5 & 0.105613 & 0.0724 & 0.05068 & 0.2058 & 20.58 \\
\hline 16 & Plastic, 2 & 21 & 0.116813 & 0.0899 & 0.06293 & 0.23 & 23 \\
\hline 17 & Plastic, 2 & 22 & 0.132626 & 0.12 & 0.084 & 0.36 & 36 \\
\hline 19 & Plastic, 3 & 15.5 & 0.162 & 0.3 & 0.21 & .484 & 48.4 \\
\hline 20 & Plastic, 3 & 8.04 & 0.170815 & 0.459 & 0.3213 & .659 & 65.9 \\
\hline
\end{tabular}

For experimental data, the Stress-Strain graph has been collected from UTM. A line plotted for initial data which data has collected for initial loading on concrete cylinder is called Phase- 1 and line plotted for final data which data has collected for final loading on concrete cylinder after an unload process has occurred in Phase-1 case is called Phase-2. Separate twelve graphs have been plotted for different 12 points (one individual graph for each cylinder) and damage parameter has been calculated for each graph using equation (11) in numerical way.

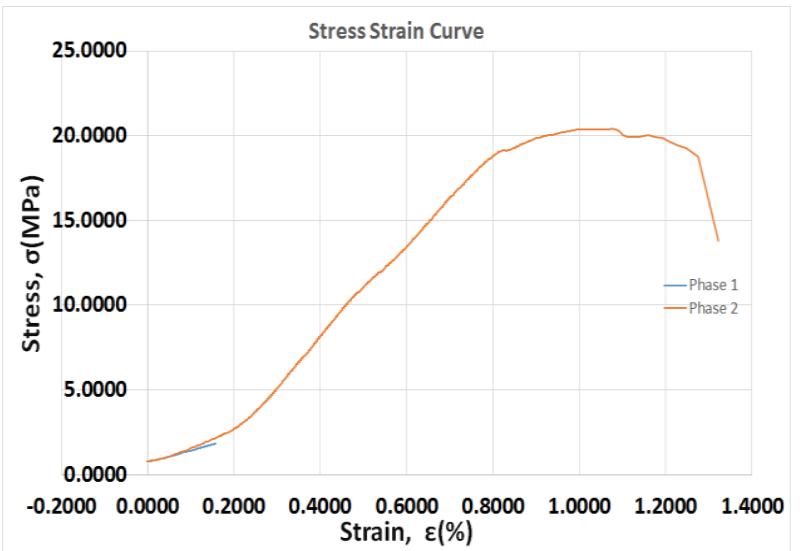

Fig. 4: Stress-Strain Curve for Initial Projected Stress $1 \mathrm{MPa}$.

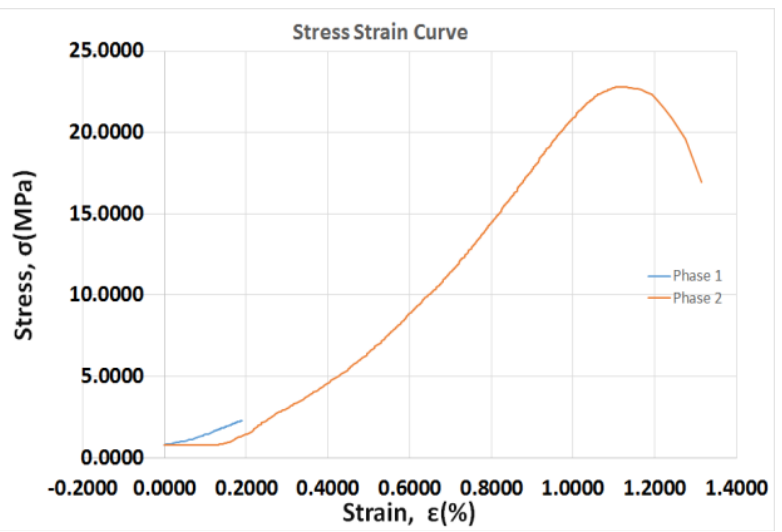

Fig. 5: Stress-Strain Curve for Initial Projected Stress 1.5 MPa. 


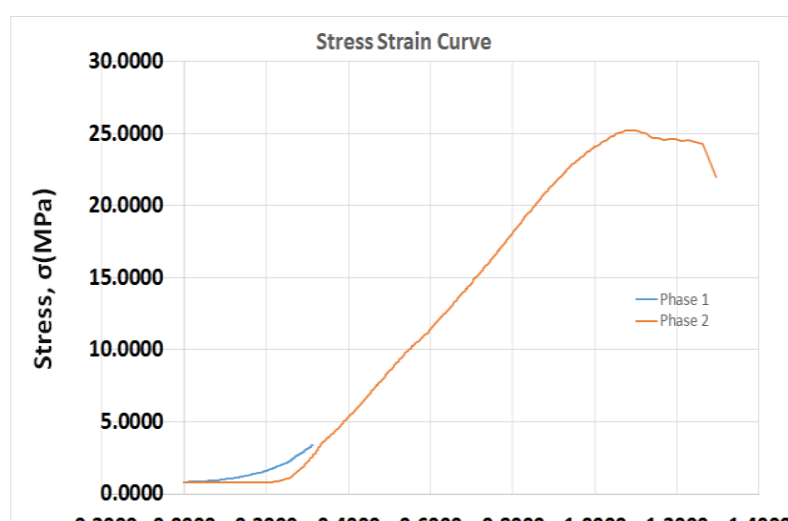

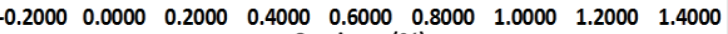
Strain, $\varepsilon(\%)$

Fig. 6: Stress-Strain Curve for Initial Projected Stress 2.5 MPa.

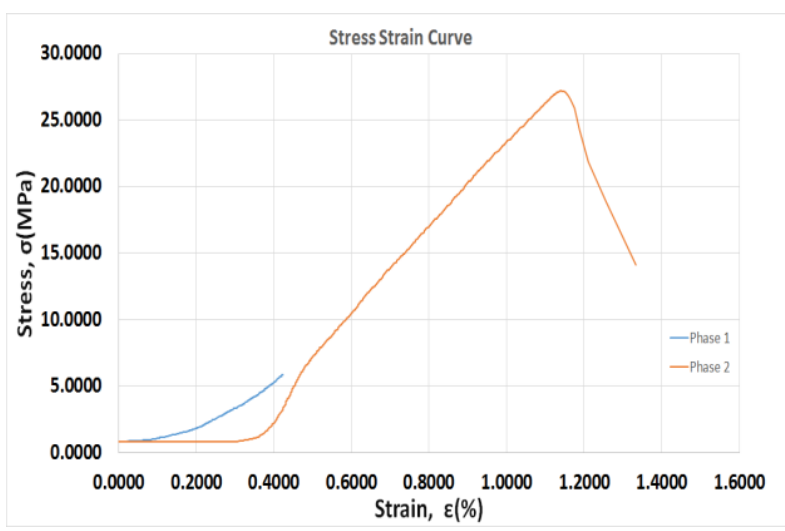

Fig. 7: Stress-Strain Curve for Initial Projected Stress $5 \mathrm{MPa}$.

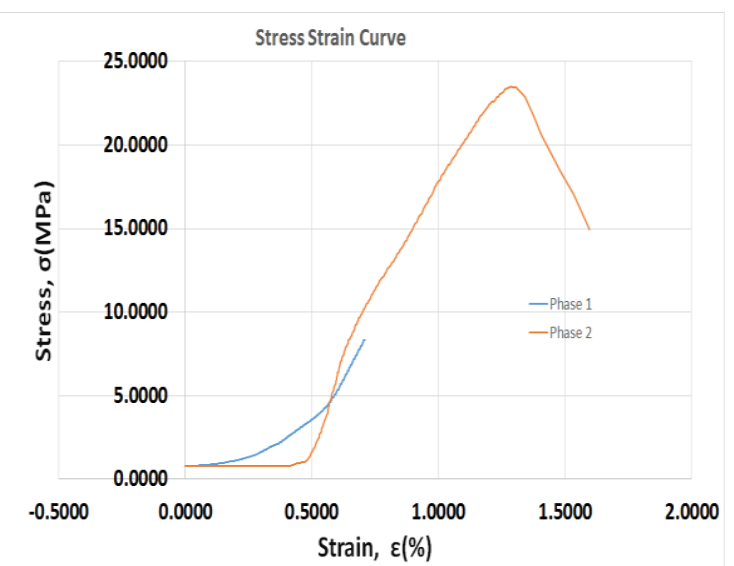

Fig. 8: Stress-Strain Curve for Initial Projected Stress 7.5MPa.

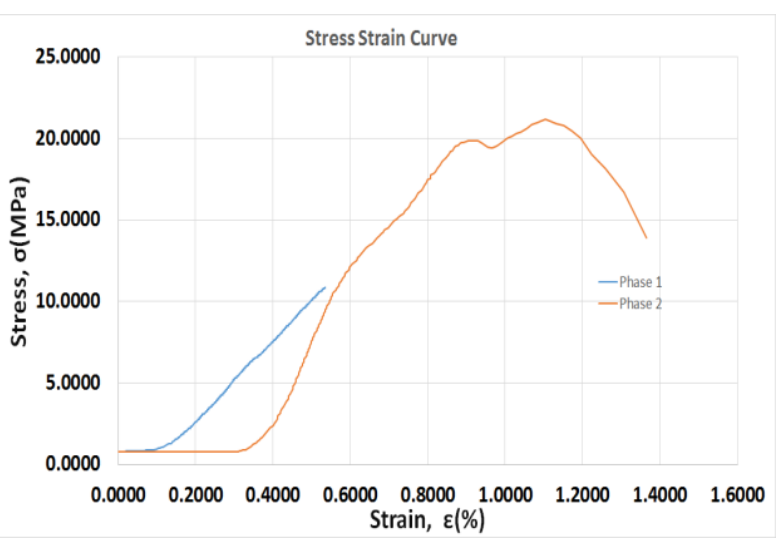

Fig. 9: Stress-Strain Curve for Initial Projected Stress 10MPa. 


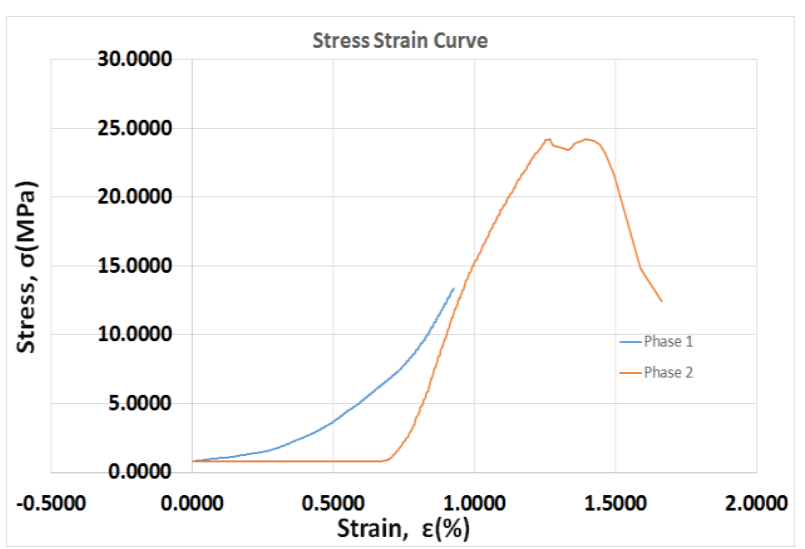

Fig. 10: Stress-Strain Curve for Initial Projected Stress $12.5 \mathrm{MPa}$

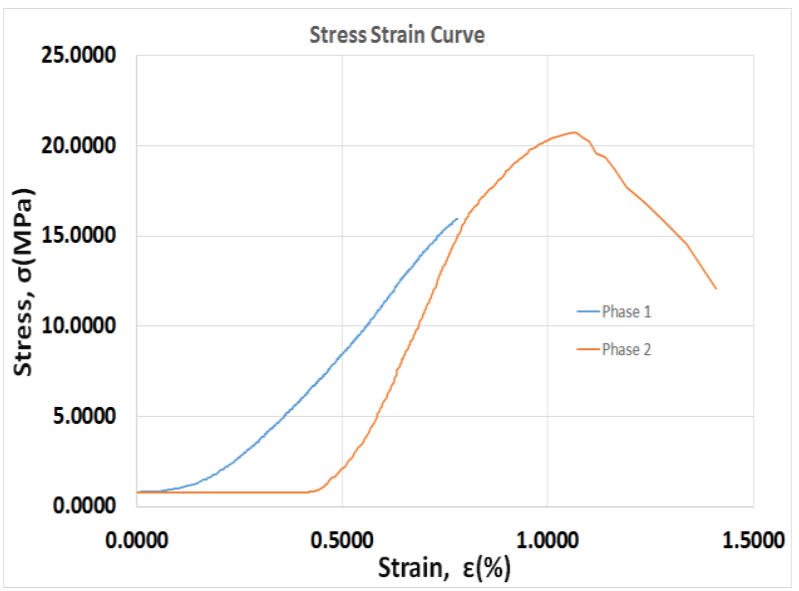

Fig. 11: Stress-Strain Curve for Initial Projected Stress 15MPa.

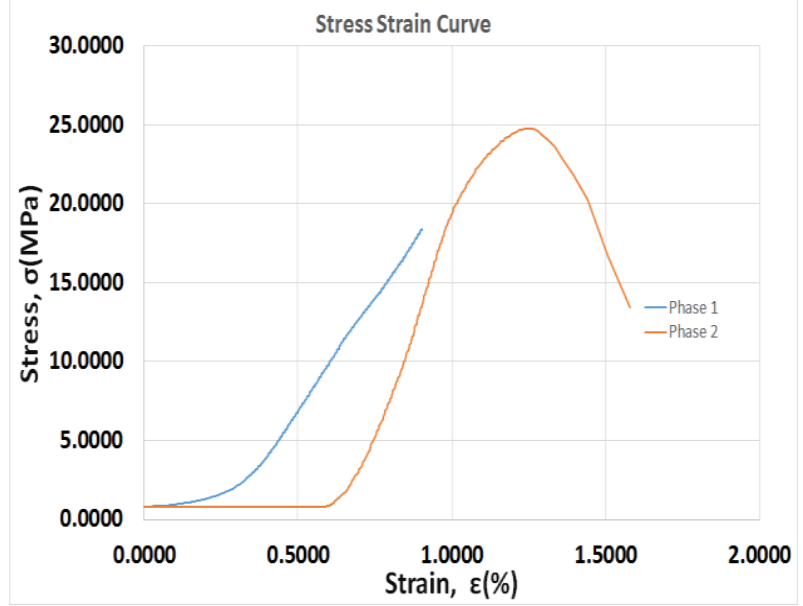

Fig. 12: Stress-Strain Curve for Initial Projected Stress 17.5MPa

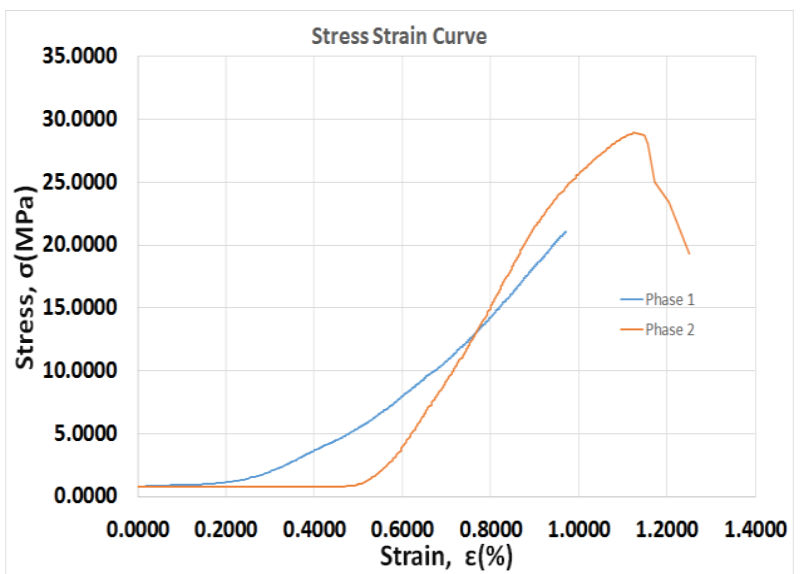

Fig. 13: Stress-Strain Curve for Initial Projected Stress 20MPa. 


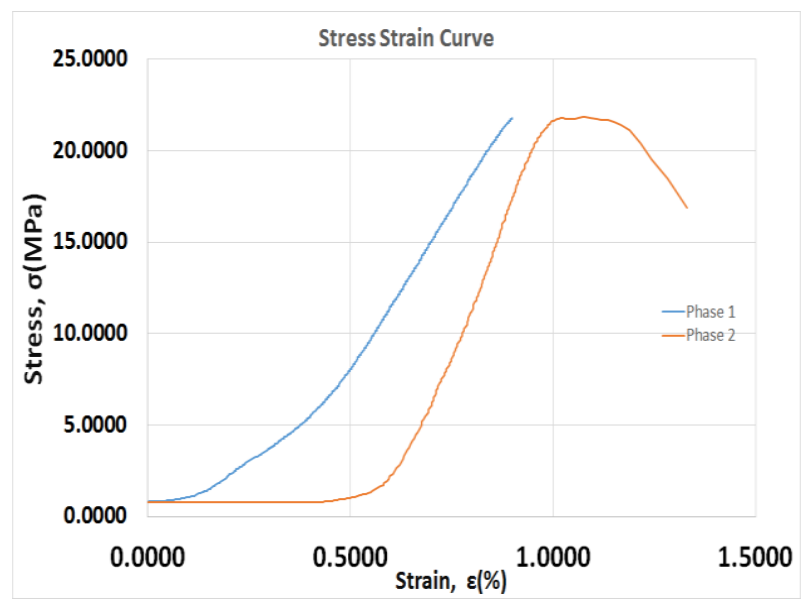

Fig. 14: Stress-Strain Curve for Initial Projected Stress 21.5MPa.

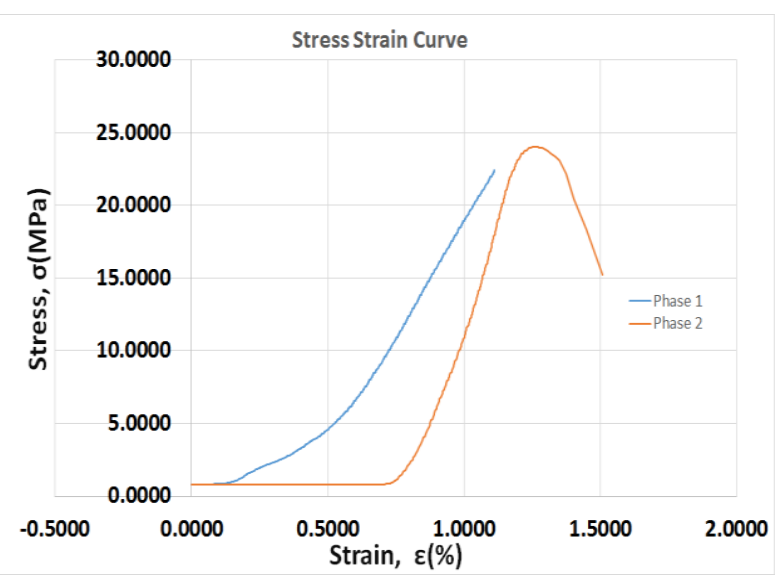

Fig. 15: Stress-Strain Curve for Initial Projected Stress 22.25MPa.

It is observed that, the graphs plotted from initial data (called Phase-1) and final data (called Phase-2) show almost same behavior and trend (Fig-4-15). In Phase-1 (Fig 4-15), concrete cylinder can take stress at initial stage which indicates that the concrete cylinder starts to take load from zero damage. Whereas in Phase-2 (Fig 4-15), concrete cylinder cannot take any stress at initial stage for a certain strain which indicate that the concrete cylinder has some damage inside the concrete that damage have occurred during Phase-1 case. From twelve graphs for different 12 points, the first point Phase- 1 and Phase-2 initial behavior is almost same which indicate that the concrete cylinder has no damage inside the concrete. Whereas in other points, Phase- 1 and Phase-2 initial behavior is not same which indicate that the concrete cylinder has some damage inside the concrete where damage is increasing from point 2 to point 12. For example, the Phase2 curve in the graph for initial projected stress $7.5 \mathrm{MPa}$ shows the cylinder takes no stress till 0.5 percent strain. This is due to damage of concrete for initial loading in Phase-1. Numerical value of elastic strain and strain for damage was taken from every graph. By using equation (11), damage was calculated and placed in table 5. Finally, the percentage of damage of concrete obtained from analysis and experiment has been compared in table 5 .

Table 5: Comparison of Concrete Damage Variable, $D_{c}$ from Analytical Data and Experimental Data

\begin{tabular}{|c|c|c|c|c|c|c|c|}
\hline \multicolumn{4}{|c|}{ Experimental Data } & \multicolumn{4}{|c|}{ Analytical Data } \\
\hline Zone & Stress, $\sigma(\mathrm{MPa})$ & dc, Damage variable & Damage, $\%$ & Zone & Stress, $\sigma(\mathrm{MPa})$ & dc Damage variable & Damage, $\%$ \\
\hline Elastic & 1.83 & 0.00 & 0 & Elastic & 1.8 & 0 & 0 \\
\hline Plastic & 2.29 & 0.11 & 11 & Elastic & 2.3 & 0 & 0 \\
\hline Plastic & 3.37 & 0.172 & 17.2 & Elastic & 3.4 & 0 & 0 \\
\hline Plastic & 5.85 & 0.226 & 22.6 & Elastic & 6.0 & 0 & 0 \\
\hline Plastic & 8.34 & 0.292 & 29.2 & Elastic & 8.3 & 0 & 0 \\
\hline Plastic & 10.8 & 0.233 & 23.3 & Plastic & 10.5 & 0.0394 & 3.94 \\
\hline Plastic & 13.4 & 0.3 & 30.00 & Plastic & 13.5 & 0.104 & 10.4 \\
\hline Plastic & 15.96 & 0.297 & 29.7 & Plastic & 16 & 0.146 & 14.6 \\
\hline Plastic & 18.42 & 0.368 & 36.8 & Plastic & 18.5 & 0.186 & 18.6 \\
\hline Plastic & 21.08 & 0.32 & 32.0 & Plastic & 21 & 0.23 & 23 \\
\hline Plastic & 21.7 & 0.303 & 30.3 & Plastic & 22 & 0.27 & 27 \\
\hline Plastic & 22.42 & 0.41 & 41.0 & Plastic & 22.5 & 0.324 & 32.4 \\
\hline
\end{tabular}




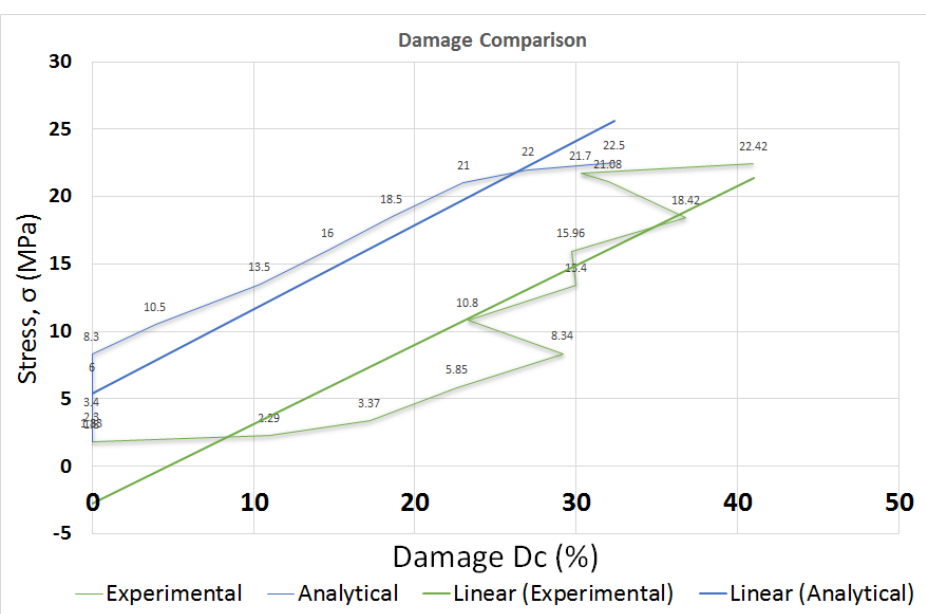

Fig. 16: Damage Comparison Graph Between from Analytical Data and Experimental Data.

\section{Conclusion}

In the final graph (fig-16), some irregular behavior in experimental stress-damage curve is observed, especially in the higher stress level, beyond 8.3MPa. The irregular behavior may be for uneven bonding of the concrete material and aggregate interlocking in different concrete cylinders.

It is observed in the final graph (fig-16), for analytical data, the concrete shows elastic behavior up to 8.3MPa stress point and no damage occur in the concrete within the limit. However, in experimental data, concrete shows elastic behavior up to only $2.28 \mathrm{MPa}$ and damage occurred beyond the stress.

The results from the experimental data deviate from the analytical data but pattern seems to have a similarity in both cases.

In initial stage (section one), for lower stress level (up to 8.3MPa), no damage can be found in analytical data but experimental data shows 29 percent damage in concrete. In second section (strain hardening brunch) damage can be found in both conditions where experimental data has presented higher percentage of damage (41 percent) than analytical data (32 percent). In the final section (the post peak zone), damage percentages have been calculated in analytical manner only.

It can be concluded that above 32 percent of concrete damaged is found for $22.5 \mathrm{MPa}$ stress in both cases.

The study has been conducted using twelve cylinders which made of same concrete mixture and environment. Further investigations are needed to establish the objective that the field data for concrete damage due to compression shows different result compare with CEBFIP model code. If it is true, a new equation should be developed to find concrete damage.

\section{References}

[1] Ananiev, S., Oz`bolt, J. (2004) 'Plastic-damage model for concrete in principal directions', In: Li, V., Leung, C.K.Y., Willam, K.J., Billington, S.L. (Eds.), Fracture Mechanics of Concrete Structures, pp. 271-278.

[2] ASTM C (1992) 127-88, Standard test method for specific gravity, and absorption of coarse aggregate. Annual book of ASTM standards. Vol 04.02

[3] ASTM C (1996) 39-96, Standard test method for compressive strength of cylindrical concrete specimens. Annual book of ASTM standards. Vol 04.02

[4] ASTM C (2001) 128-01, Standard test method for density, relative density (specific gravity), and absorption of fine aggregate. Annual book of ASTM standards. Vol 04.02

[5] ASTM C (2002) 136, Standard test method for sieve analysis of fine and coarse aggregates. Annual book of ASTM standards. Vol 04.02

[6] ASTM C (2002) 150, Standard Specification for Portland cement. Annual book of ASTM standards. Vol 04.02

[7] ASTM C (2003) 31-03a, Standard Practice for Making and Curing Concrete Test Specimens in the Field. Annual book of ASTM standards. Vol 04.02

[8] ASTM C (2004) 94-04, Standard Specification for ready mix concrete. Annual book of ASTM standards. Vol 04.02

[9] ASTM C (2008) 33, Standard Specification for concrete aggregates. Annual book of ASTM standards. Vol 04.02

[10] ASTM C (2010) 143-10a, Standard Test Method for Slump Hydraulic-cement Concrete. Annual book of ASTM standards. Vol 04.02

[11] Bazant, Z.P. (1978) 'Endochronic inelasticity and incremental plasticity', International Journal of Solids Structures, Vol 14, No 9, pp. 691-714. https://doi.org/10.1016/0020-7683(78)90029-X.

[12] BNBC (2006), Bangladesh National Building Code. Vol 2

[13] Carol, I., Rizzi, E., Willam, K.J. (2001), 'On the formulation of anisotropic elastics degradation. II. Generalized pseudo-Rankine model for tensile damage', International Journal of Solids and Structures, Vol 38, No 4, pp. 519-546. https://doi.org/10.1016/S0020-7683(00)00031-7.

[14] CEB-FIP (1993), Model Code 1990, Thomas Telford, London.

[15] Chen, A.C., Chen, W.F. (1975) 'Constitutive relations for concrete', Journal of the Engineering Mechanics Division, ASCE, Vol 101, No 4, pp. 465-481.

[16] Chen, E.S., Buyukozturk, O. (1985) 'Constitutive model for concrete in cyclic compression', Journal of the Engineering Mechanics Division, ASCE, Vol 111, No 6 pp. 797-814. https://doi.org/10.1061/(ASCE)0733-9399(1985)111:6(797).

[17] Dragon, A., Mro' z, Z. (1979) 'A continuum model for plastic-brittle behavior of rock and concrete', International Journal of Engineering Science, Vol 17, pp. 121-137. https://doi.org/10.1016/0020-7225(79)90058-2.

[18] Este, G., Willam, K.J. (1994) 'A fracture-energy based constitutive formulation for inelastic behavior of plain concrete', Journal of Engineering Mechanics, ASCE, Vol 120, No 9, pp. 1983-2011. https://doi.org/10.1061/(ASCE)0733-9399(1994)120:9(1983).

[19] Gatuingt, F., Pijaudier-Cabot, G. (2002) 'Coupled damage and plasticity modeling in transient dynamic analysis of concrete', International Journal of Numerical and Analytical Methods in Geomechanics, Vol 26, No 1, pp. 1-24. https://doi.org/10.1002/nag.188.

[20] Grassl, P., Lundgren, K., Gylltoft, K. (2002) ‘Concrete in compression: a plasticity theory with a novel hardening law', International Journal of Solids and Structures, Vol 39, No 20, pp. 5205-5223. https://doi.org/10.1016/S0020-7683(02)00408-0.

[21] Hansen, E., Willam, K., Carol, I. (2001) 'A two-surface anisotropic damage/plasticity model for plain concrete', in: de Borst, R., Mazars, J., Pijaudier-Cabot, G., van Mier, J.G.M. (Eds.), Fracture Mechanics of Concrete Structures. Balkema, Lisse, pp. 549-556. 
[22] Imran, I., Pantazopoulou, S.J. (1996) 'Experimental study of plain concrete under triaxial stress', ACI Materials Journal, Vol 93, No 6, pp. 589601. https://doi.org/10.14359/9865.

[23] Jason, L., Pijaudier-Cabot, G., Huerta, A., Crouch, R., Ghavamian, S. (2004) 'An elastic plastic damage formulation for the behavior of concrete', In: Li, V., Leung, C.K.Y., William, K.J., Billington, S.L. (Eds.), Fracture Mechanics of Concrete Structures, Ia-FraMCos-5, Vail, Colorado, USA, pp. 549-556.

[24] Ju, J.W. (1989) 'On energy-based coupled elastoplastic damage theories: constitutive modeling and computational aspects', International Journal of Solids and Structures, Vol 25, No 7, pp. 803-833. https://doi.org/10.1016/0020-7683(89)90015-2.

[25] Karabinis, A.I., Kiousis, P.D. (1994) 'Effects of confinement on concrete columns: a plasticity theory approach', ASCE Journal of Structural Engineering, Vol 120, No 9, pp. 2747-2767. https://doi.org/10.1061/(ASCE)0733-9445(1994)120:9(2747).

[26] Krajcinovic, D. (1983) 'Continuum damage mechanics', Applied Mechanics Reviews Vol 37, pp. 1-6.

[27] Kratzig, W., Polling, R. (2004) 'An elasto-plastic damage model for reinforced concrete with minimum number of material parameters', Computers and Structures, Vol 82, No 15, pp. 1201-1215. https://doi.org/10.1016/j.compstruc.2004.03.002.

[28] Loland, K.E. (1980) 'Continuous damage model for load-response estimation of concrete', Cement \& Concrete Research, Vol 10, No 3, pp. 395402. https://doi.org/10.1016/0008-8846(80)90115-5.

[29] Lubarda, V.A., Kracjinvovic, D., Mastilovic, S. (1994) 'Damage model for brittle elastic solids with unequal tensile and compressive strength', Engineering Fracture Mechanics, Vol 49, pp. 681-697. https://doi.org/10.1016/0013-7944(94)90033-7.

[30] Lubliner, J., Oliver, J., Oller, S., Onate, E. (1989) 'A plastic-damage model for concrete', International Journal of Solids Structures, Vol 25, No 3, pp. 299-326. https://doi.org/10.1016/0020-7683(89)90050-4.

[31] Menetrey, Ph., Willam, K.J. (1995) 'Triaxial failure criterion for concrete and its generalization', ACI Structural Journal, Vol 92, No 3, pp. 311318. https://doi.org/10.14359/1132.

[32] Neville, A.M (1963) 'Properties of Concrete', Pearson Education, NJ.

[33] Onate, E., Oller, S., Oliver, S., Lubliner, J. (1988) 'A constitutive model of concrete based on the incremental theory of plasticity', Engineering Computations, Vol 5, No 4, pp. 309-319. https://doi.org/10.1108/eb023750.

[34] Ortiz, M., Popov, E.P. (1982) 'Plain concrete as a composite material', Mechanics of Material, Vol 1, pp. 139-150. https://doi.org/10.1016/01676636(82)90042-4

[35] Resende, L., Martin, J.B. (1984), 'A progressive damage continuum model for granular materials', Computer Methods in Applied Mechanics and Engineering, Vol 42, No 1, pp. 1-18. https://doi.org/10.1016/0045-7825(84)90029-X.

[36] Salari, M.R., Saeb, S., Willam, K.J., Patchet, S.J., Carrasco, R.C. (2004) 'A coupled elastoplastic damage model for geomaterials', Computer Methods in Applied Mechanics and Engineering, Vol 193, pp. 2625-2643. https://doi.org/10.1016/j.cma.2003.11.013.

[37] Schreyer, H.L. (1983) 'Third-invariant plasticity theory for frictional materials', Journal of Structural Mechanics, Vol 11, No 2, pp. 177-196. https://doi.org/10.1080/03601218308907440.

[38] Simo, J.C., Ju, J.W. (1987a) 'Strain and stress-based continuum damage. Model. Part I: formulation', International Journal of Solids and Structures, Vol 23, No 7, pp. 821-840. https://doi.org/10.1016/0020-7683(87)90083-7.

[39] Simo, J.C., Ju, J.W. (1987b) 'Strain- and stress-based continuum damage models. Part II: computational aspects', International Journal for Solids and Structures, Vol 23, No 7, pp. 841-869. https://doi.org/10.1016/0020-7683(87)90084-9.

[40] Van Mier, J. G. M. (1984) 'Strain-softening of concrete under multiaxial loading conditions', PHD thesis, Techn. Univ. Eindhoven. doi.org/10.6100/IR145193

[41] Voyiadjis, G.Z., Abu-Lebdeh, T.M. (1994) 'Plasticity model for concrete using the bounding surface concept; International Journal of Plasticity, Vol 10, No1, pp. 1-21. https://doi.org/10.1016/0749-6419(94)90051-5.

[42] Willam, K.J., Warnke, E.P. (1974) 'Constitutive model for the triaxial behavior of concrete', In: Concrete Structures Subjected to Triaxial Stresses. Vol. 19 of IABSE Report, International Association of Bridge and Structural Engineers, Zurich, pp. 1-30.

[43] Winkler, K. and Stangenberg, F. (2008) 'Numerical Analysis of Punching Shear Failure of Reinforced Concrete Slabs', ABAQUS Users' Conference.

[44] Pölling, R., “Eine praxisnahe, schädigungsorientierte Materialbeschreibung für Stahlbeton” Dissertation, Ruhr-Universität Bochum, 2000. 